\title{
O COMPORTAMENTO DOS GESTORES OPERACIONAIS DA EMPRESA BRASILEIRA DE CORREIOS E TELÉGRAFOS: RELATO DE EXPERIÊNCIA SOBRE A PROCRASTINAÇÃO NA CONDUÇÃO DE PROCESSOS ADMINISTRATIVOS DISCIPLINARES
}

\section{ARTIGO ORIGINAL}

SOUZA, Fernanda Leobons de ${ }^{1}$

SOUZA, Fernanda Leobons de. O comportamento dos gestores operacionais da empresa Brasileira de correios e telégrafos: relato de experiência sobre a procrastinação na condução de processos administrativos disciplinares. Revista Científica Multidisciplinar Núcleo do Conhecimento. Ano. 06, Ed. 12, Vol. 03, pp. 108-120. Dezembro de 2021. ISSN: 2448-0959, Link de acesso: https://www.nucleodoconhecimento.com.br/administracao/gestores-operacionais, DOI: 10.32749/nucleodoconhecimento.com.br/administracao/gestores-operacionais

\section{RESUMO}

O artigo trata-se de um relato de experiência sobre os principais padrões de comportamento, tais como: falta de comprometimento e falta de motivação, que levam grande parte dos líderes operacionais da Empresa Brasileira de Correios e Telégrafos (ECT) a postergar a conclusão dos PADs (Processos Administrativos Disciplinares), por entenderem que eles ajudam a promover um clima organizacional desfavorável, comprometendo, dessa forma, a relação entre o gestor e seus subordinados. Tendo em vista este cenário, foi levantada a seguinte questão norteadora: quais os principais padrões de comportamento dos gestores com relação a conclusão das PADs e por que eles acabam postergando a conclusão delas? O estudo tem como objetivo principal apresentar um relato de experiência

\footnotetext{
${ }^{1}$ Pós-graduada (Lato sensu) em Gestão Pública, pela UNIBF, Pós-graduada (Lato sensu) em Administração de Recursos Humanos no Setor Público, pela UNIBF, Pós-graduada em Administração Patrimonial em Organizações Públicas (Lato sensu), pela UNIBF, Graduada em Administração de Empresas (Bacharelado), pela Universidade Veiga de Almeida. ORCID: https://orcid.org/0000-0003-1860-4737.
}

RC: 102979

Disponível em: https://www.nucleodoconhecimento.com.br/administracao/gestoresoperacionais 
sobre o comportamento dos gestores operacionais que trabalham na ECT, quanto à procrastinação na condução de processos administrativos disciplinares. Para tanto, através da metodologia de pesquisa bibliográfica e documental e, sobretudo, do relato de experiência na ECT, pretende-se apresentar no artigo, uma contextualização do que ocorre no âmbito da instituição e os fatores que implicam o atraso no saneamento de processos administrativos disciplinares autuados, por exemplo, em virtude do mau uso de smartphones por parte de seus funcionários. A autora do presente artigo trabalha na ECT há dezesseis anos, e participa desde o ano de 2020 da equipe responsável por oferecer suporte aos gestores da área operacional, quanto às dúvidas pertinentes à movimentação das PADs. Constatouse que o SEI (Sistema Eletrônico de Informações) foi criado pelo Tribunal Regional Federal da 4르 Região, ente 2011 e 2013, e fornecido gratuitamente às instituições da administração pública, inclusive à ECT, como uma ferramenta eficaz para a gestão eletrônica dos documentos oficiais. O sistema em questão é utilizado para instauração e acompanhamento de processos administrativos, inclusive dos PADs que visam à identificação dos funcionários responsáveis pelas avarias e danos causados aos aparelhos com os quais os carteiros realizam a entrega dos objetos postais aos respectivos destinatários, gerando como consequências: a insatisfação dos clientes e eventuais prejuízos para a empresa.

Palavras-chave: Processos disciplinares, SEI, sustentabilidade.

\section{INTRODUÇÃO}

No contexto atual, busca-se cada vez mais transparência das atitudes dos funcionários públicos e dos registros documentais arquivados na Administração Pública. Essa preocupação tornou-se mais evidente, desde a criação da Lei no 12.527, de 18 de novembro de 2011 — Lei de Acesso à Informação — LAI (BRASIL, 2011).

Em consonância à LAI (BRASIL, 2011), segundo Saraiva (2018), o Tribunal Regional Federal da 4⿳亠丷厂 Região (TRF4) criou, entre 2011 e 2013, uma ferramenta inovadora e

RC: 102979

Disponível em: https://www.nucleodoconhecimento.com.br/administracao/gestoresoperacionais 
eficaz na gestão eletrônica de documentos oficiais das instituições públicas, denominada SEI (Sistema Eletrônico de informações).

Conforme Saraiva (2018, p. 1):

O SEI foi desenvolvido pelo Tribunal Regional Federal da 4ª Região (TRF4), cedido gratuitamente para os demais órgãos públicos, e é hoje o sistema que deve ser preferencialmente adotado por toda a administração pública federal, conforme a Portaria do Ministério do Planejamento, Desenvolvimento e Gestão no 17 , de 7 de fevereiro de 2018.

O presente artigo tem como objetivo principal apresentar um relato de experiência sobre o comportamento dos gestores operacionais que trabalham na Empresa Brasileira de Correios e Telégrafos (ECT), quanto à procrastinação na condução de processos administrativos disciplinares - PADs, respondendo à questão norteadora do estudo: quais os principais padrões de comportamento dos gestores com relação a conclusão das PADs e por que eles acabam postergando a conclusão delas?

Como a autora trabalha nessa instituição federal (que presta serviços essenciais na área de Logística) há dezesseis anos e, desde o ano de 2020, participa da equipe responsável pelo apoio administrativo aos gestores operacionais, quanto à conclusão dos processos disciplinares, sua experiência diária junto a esses líderes serviu como meio de embasamento para o estudo realizado.

Para tanto, através da metodologia de pesquisa bibliográfica, documental e, sobretudo, do relato de sua experiência profissional, a autora pretende apresentar uma contextualização do que ocorre no âmbito da instituição, e que implica atraso no saneamento de processos administrativos disciplinares autuados, por exemplo, em virtude do mau uso de smartphones por parte de seus funcionários.

Em razão do tempo cada vez mais escasso para a realização das atividades operacionais da empresa estudada, a autora pôde constatar, através de observação criteriosa, que os líderes se abstinham de suas responsabilidades quanto às questões essencialmente burocráticas, não levando em consideração que essas

RC: 102979

Disponível em: https://www.nucleodoconhecimento.com.br/administracao/gestoresoperacionais 
tarefas também representam atividades fundamentais à liderança e merecem atenção por parte dos gestores, dentro de qualquer organização.

A abordagem do estudo realizado pela autora, a partir do relato de sua experiência, através do apoio administrativo fornecido aos gestores do setor operacional da ECT, visa ao entendimento dos gestores públicos sobre a importância dos processos supracitados, uma vez que contribuem para a eficácia das atitudes da empresa pública, frente aos clientes, melhorando assim, sua imagem diante da população e aumentando, desta forma, a confiança em seus serviços, o que implica no crescimento dos lucros da instituição, garantindo a sua sobrevivência, mesmo diante do ambiente competitivo em que se encontra.

\section{RELATO DE EXPERIÊNCIA}

\subsection{PROCESSO DE IMPLEMENTAÇÃO DO SEI NA ECT}

A Empresa Brasileira de Correios e Telégrafos (ECT), instituição pública que iniciou suas atividades postais em 1663 (CORREIOS, 2019), vem se modernizando constantemente, através da busca por melhoria contínua dos serviços prestados à população, garantindo assim a satisfação a seus clientes e sua consequente sustentabilidade.

Conforme Saraiva (2018), o SEI (Sistema Eletrônico de Informações) foi criado entre 2011 e 2013, pelo TRF4, sendo disponibilizado às demais instituições públicas, a exemplo da empresa em estudo.

No final de 2016, a Alta Direção da empresa investigada incentivou seus funcionários a concluírem um curso, disponibilizado na modalidade à distância, dentro da plataforma da Universidade Virtual dos Correios - UNIVIRTUAL, com as orientações necessárias à utilização do novo sistema, porém grande parte de seus funcionários não estavam preparados para a nova tendência dos processos administrativos.

RC: 102979

Disponível em: https://www.nucleodoconhecimento.com.br/administracao/gestoresoperacionais 
O processo de implementação do SEI deu-se de forma lenta e gradual na ECT, sendo consolidado a partir de 2017, coexistindo com o antigo sistema, como uma ferramenta eficaz para a gestão eletrônica de documentos, incluindo a autuação de processos administrativos.

Houve resistência inicial de muitos empregados, habituados a lidar com processos físicos, em meio a folhas de papel e que, de repente, viram-se obrigados a utilizar a nova ferramenta para todos os tipos de documentos oficiais de comunicação utilizados pela organização analisada, tais como: memorandos, ofícios e cartas.

A maior dificuldade dos profissionais, conforme a observação realizada pela autora do presente artigo, que trabalha na instituição em análise há dezesseis anos, era assimilar que seria necessária a criação de um processo administrativo para qualquer setor que precisasse elaborar um documento para fins de comunicação oficial.

O novo sistema propunha agilidade na comunicação da ECT internamente e externamente, segundo a análise da autora, pois oferecia, dentre vários tipos de inovação: a disponibilidade do recurso de assinatura eletrônica. Ou seja, antes da utilização do SEI, um documento necessitaria da assinatura em um documento físico. Por exemplo, o gerente da área responsável pela elaboração de um memorando teria que assiná-lo, antes de o documento seguir para a área-fim. Desta forma, se o gerente estivesse viajando a negócios, o documento teria que aguardar até o seu retorno, para que sua assinatura fosse colhida, e o documento devidamente encaminhado para o setor-fim.

Mesmo com todo o avanço ocasionado pelo SEI, houve gerentes e funcionários contrários à inovação, pois seria necessária a adequação aos novos procedimentos, que incluíam a redução nos prazos para a resolução dos problemas identificados nos processos administrativos. Portanto, haveria maior cobrança para o atingimento das metas demandadas pelos setores da organização, aos quais os funcionários estavam subordinados.

RC: 102979

Disponível em: https://www.nucleodoconhecimento.com.br/administracao/gestoresoperacionais 
O SEI promete ainda mais inovações, no que diz respeito a encurtar as distâncias entre os órgãos institucionais da esfera pública.

Segundo Saraiva (2018), “... a iniciativa de um processo eletrônico nacional tem como meta alcançar estados e municípios". Isso significa que a próxima fase de implantação do sistema SEI será a de tramitação de processos entre diversas instituições, permitindo uma maior integração entre os vários órgãos da administração pública, que acarretará agilidade na troca de informação e na rápida resolução das questões demandadas nos processos públicos.

\subsection{OS PROCESSOS ADMINISTRATIVOS DISCIPLINARES DA ECT}

Considerando que Lei ํ․ 8.112/1990 abrange somente as normas aplicadas aos servidores públicos, houve a necessidade de a ECT desenvolver um manual, o MANCOD - Manual de Controle Disciplinar, cujas normas internas pudessem ser aplicadas à situação de seus empregados públicos (regidos pela Consolidação das Leis Trabalhistas - CLT)

Para tanto, a empresa utiliza-se de processos administrativos disciplinares - PADs, alinhados às normas internas e à CLT, de forma a garantir a ampla defesa para os funcionários que sejam o alvo de alguma investigação em virtude de uma conduta supostamente irregular.

Processos disciplinares são autuados, quando uma conduta funcional irregular é identificada, após a devida investigação preliminar, constatando-se a responsabilização de um dos funcionários da empresa sobre a norma do regulamento interno infringido.

A autora trabalha na empresa analisada desde o ano de 2005 e, desde o ano de 2020, integra a equipe da gerência responsável por oferecer suporte aos gestores operacionais, em relação à finalização dos processos administrativos disciplinares, autuados no SEI. 
Portanto, através da observação criteriosa, lidando diretamente com esses líderes e esclarecendo suas dúvidas quanto aos documentos necessários à composição e encerramento de tais processos, a autora constatou os motivos principais alegados pelos gestores, para o não atendimento à demanda estabelecida pela empresa, conforme MANCOD (2020, p.3), que define no módulo 1; capítulo 3; subitem 1.4.3:

As Providências Preliminares deverão ser iniciadas logo após a autoridade competente tomar ciência da suposta irregularidade funcional e deverão ser concluídas, no prazo máximo de 15 (quinze) dias, podendo ser prorrogado, motivadamente, por igual período.

Segundo preconizado no módulo 1, capítulo 3 do MANCOD (2020), os processos administrativos disciplinares (PADs) possuem um Apurador Direto, que é o Chefe do órgão de lotação do funcionário identificado como responsável pela infração. Esse gestor será o responsável pela condução do processo disciplinar junto ao funcionário, colhendo suas justificativas que serão anexadas aos autos, assim como será responsável pela elaboração de um documento denominado Relatório de Providências Preliminares, de conclusão favorável ou desfavorável à absolvição do funcionário, diante das provas contidas nos autos e da defesa apresentada.

No caso de o funcionário apresentar comprovação de que é isento, frente aos questionamentos apontados, ele será absolvido e o processo consequentemente, arquivado. Entretanto, caso seja confirmada a autoria da infração pelo funcionário, após suas alegações finais, o Gestor encaminhará o processo para a autoridade competente, que fará o respectivo Julgamento Disciplinar, mediante as provas apresentadas.

Esses processos possuem prazos estabelecidos pelo Manual de Controle Disciplinar da empresa, ao qual os gestores e os subordinados possuem livre acesso, para a busca de informações, através da intranet, ou através do acesso ao site da empresa. Portanto, não há justificativa para o funcionário ou o gestor alegarem desconhecimento das normas e sanções aplicadas, contidas no referido manual. 
Entretanto, mesmo com toda a informação de fácil acesso, há gestores que terminam por procrastinar a conclusão desses processos, em virtude de uma série de fatores observados e que serão apresentados a seguir.

\subsection{O COMPORTAMENTO OBSERVADO NOS GESTORES OPERACIONAIS DA ECT, QUANTO À PROCRASTINAÇÃO NA CONDUÇÃO DOS PROCESSOS ADMINISTRATIVOS DISCIPLINARES}

A autora do presente artigo identificou, com o estudo realizado como integrante da equipe de apoio administrativo aos gestores operacionais, desde o ano de 2020, que havia um comportamento procrastinador em relação à resolução deles, em virtude de uma série de fatores.

O trabalho realizado pela autora e os demais funcionários da equipe da gerência (que terá seu nome preservado) da ECT, deu-se da seguinte forma: houve uma reunião em abril de 2020 , entre os membros da equipe, na qual foram estabelecidos os critérios necessários à avaliação das pendências identificadas em cada processo administrativo disciplinar.

Após a reunião, o gerente responsável pela equipe administrativa da qual a autora faz parte, encaminhou por e-mail as cobranças realizadas pela área da instituição, que representa a Corregedoria Estadual do RJ.

A Gerência - a qual a autora do artigo é subordinada - compõe-se de vinte e três unidades operacionais, dentre as quais, estão inseridos os Centros de Distribuição Domiciliária e os Centros de Entrega de Encomendas.

Na reunião supracitada, houve a distribuição dessas unidades entre os três

membros da equipe de apoio administrativo. Ou seja, cada membro teria que estabelecer o contato com os respectivos gerentes das unidades pré-estabelecidas, 
para solicitar a regularização das pendências constatadas nos processos administrativos, tais como: falta de documentos essenciais à Investigação Preliminar, falta de assinatura eletrônica dos relatórios anexados aos autos etc.

A interação ocorrida entre os membros da equipe de apoio e os gerentes das unidades proporcionou maior percepção das dificuldades relatadas pelos gerentes, para finalizar os processos administrativos disciplinares. Entre elas, destacaram-se: a falta de entendimento dos gestores sobre a importância de esses processos serem saneados com agilidade; a falta de tempo alegada pelos gestores para rotinas efetivamente administrativas, frente a outras atividades que os mesmos tinham por obrigação executar em sua rotina diária e que são essencialmente operacionais (como: recebimento e acompanhamento da carga, além da triagem e entrega dos objetos postais).

Com a pandemia, no início de 2020, houve drástica redução no quadro do efetivo presencial da ECT. Ou seja, os funcionários das unidades que possuíam doenças pré-existentes e os funcionários acima de sessenta anos foram afastados, trabalhando remotamente, como medida de prevenção à doença que acabara de se alastrar no Brasil e no mundo.

Portanto, os gestores operacionais e os demais empregados das unidades ficaram sobrecarregados. E, desta forma, houve reuniões virtuais com os líderes, a fim de evitar aglomerações nas seções da empresa, com o intuito da continuidade do apoio para a conclusão dos PADs.

A equipe de apoio administrativo também estabeleceu contato com os líderes operacionais, por mensagem via e-mail e/ou celular. Portanto, ao serem questionados, através dessas mensagens, os gestores apresentaram as alegações supracitadas, como justificativa para 0 não atendimento às demandas da Corregedoria da empresa, dentro das normas estabelecidas pelo MANCOD (2020), para a finalização dos PADs no sistema. 
Outra questão observada pela autora, para a falta de motivação em relação ao saneamento e finalização desses processos, foi a alegação dos gestores de que o clima organizacional se tornava desfavorável, a partir do momento em que eles necessitavam informar ao funcionário (responsável pela infração) sobre a sanção disciplinar e/ou pecuniária a ser aplicada.

Segundo Silva (2000, p. 241):

(...) o patrimônio do Estado, como matéria administrável, isto é, como objeto da gestão patrimonial desempenhada pelos órgãos da administração, é o conjunto de bens, valores, créditos e obrigações de conteúdo econômico e avaliável em moeda que a Fazenda Pública possui e utiliza na consecução de seus objetivos.

Portanto, torna-se imprescindível a conclusão ágil de processos administrativos disciplinares, em especial os que são autuados para a recuperação do dano ao erário da ECT.

Um exemplo de PAD autuado na ECT, para a responsabilização pecuniária proveniente de uma conduta irregular praticada por um funcionário da instituição, é o relativo ao mau uso de smartphones (aparelhos utilizados pelos carteiros para registrar a entrega dos objetos postais aos respectivos destinatários). Assim, a rápida conclusão desses PADS denota uma maior preocupação da empresa quanto à administração de seu patrimônio, frente aos órgãos de auditoria pública.

Os smartphones foram responsáveis pela modernização da ECT, frente às entregas realizadas pelos carteiros, que antes dispunham de listas físicas para a assinatura dos destinatários e, com o avanço da tecnologia, atualmente utilizam os smartphones para a captura da assinatura, através de um sistema especializado integrado ao rastreamento do objeto, que insere a baixa de entrega simultaneamente.

Esse sistema agiliza os procedimentos de entrega, pois viabiliza a informação para o remetente no ato da entrega, o que antes só era possível no retorno dos carteiros 
aos respectivos Centros de Distribuição, com a baixa realizada manualmente, objeto a objeto.

Portanto, quando os carteiros comprometem o tempo de vida útil desses aparelhos, em virtude de queda, mesmo que acidentalmente, acabam por reduzir os recursos existentes na empresa e, como se trata de uma empresa pública, a substituição dos aparelhos com defeito não é realizada rapidamente, o que deixa a unidade sem aquele recurso durante certo tempo, até ocorrer a troca.

A empresa realiza o repasse de seu prejuízo, quanto à inviabilização devido ao mau uso do smartphone, ao carteiro responsável pela queda ou avaria, para que o mesmo tenha consciência de que, como empregado público, tem o dever e a responsabilidade de zelar pelo bem que Ihe foi entregue para a execução de suas atividades.

Desta forma, há uma maior consciência desses funcionários, quanto ao correto manuseio e guarda desse aparelho, uma vez que representa objeto de controle patrimonial da instituição.

\section{CONSIDERAÇÕES FINAIS}

Atualmente, a preocupação de empresas públicas quanto à transparência de seus processos, principalmente após a Lei de Acesso à Informação (BRASIL, 2011), requer um esforço conjunto dos empregados que compõem as instituições, para que possam conquistar a fidelização de seus clientes e a consequente melhoria de sua imagem junto à sociedade, além de garantir sua sustentabilidade.

O presente artigo buscou, através da metodologia de pesquisa bibliográfica e documental, e, sobretudo, do relato de experiência da autora, responder à questão norteadora: quais os principais padrões de comportamento dos gestores com relação a conclusão das PADs e por que eles acabam postergando a conclusão delas? Ou seja, o artigo propôs-se a apresentar um relato de experiência sobre o comportamento dos gestores operacionais da Empresa Brasileira de Correios e 
Telégrafos (ECT), quanto à condução dos processos administrativos disciplinares, especialmente àqueles que dizem respeito ao mau uso dos smartphones pelos carteiros, tendo como base a contextualização demonstrada nos três estudos de caso.

Os smartphones representam um grande avanço tecnológico para a ECT. Portanto, é imprescindível que os carteiros tenham a consciência de zelar pelo patrimônio da empresa, uma vez que, para a substituição dos mesmos, em virtude de avaria e outros fatores que inviabilizam sua utilização, é necessário um processo administrativo disciplinar, no qual é identificado o responsável pelo prejuízo causado à instituição e, a partir daí, seja definido o valor do conserto equivalente ao defeito e sejam aplicadas as sanções disciplinares e pecuniárias (correspondentes ao dano ao erário).

No começo da autuação e acompanhamento dos processos administrativos através do SEI, houve muita resistência dos gestores em realizar o curso ofertado para aprendizado de todas as ferramentas e modelos de correspondência disponíveis no sistema, conforme observação realizada pela autora, em seu ambiente de trabalho.

O estudo teve como principal foco a condução dos gestores operacionais sobre os processos administrativos disciplinares, como exemplo, os relativos ao mau uso dos smartphones. Contudo, a ECT, assim como outras organizações públicas, utiliza o sistema SEI para averiguação de outras irregularidades constatadas, quanto à conduta funcional de seus empregados, conforme preconiza o MANCOD Manual de Conduta Disciplinar (2020), além da legislação aplicável a empregados públicos regidos pela CLT.

Embora no ano de 2020, tenha ocorrido uma cobrança maior sobre o papel dos gestores na condução dos processos, a autora percebeu uma redução significativa da resistência à utilização do SEI. Entretanto, ainda há um longo caminho a ser trilhado. 
Além disso, autora pretende, com o presente artigo, sugerir estudos futuros sobre ações a serem realizadas pela gerência responsável pela capacitação dos gestores operacionais, pois com incentivo ao aprendizado, há grande expectativa de melhorias no comportamento dos líderes e da equipe, frente às atribuições que the são confiadas.

\section{REFERÊNCIAS}

BRASIL. Lei № 8.112, de 11 de dezembro de 1990. Dispõe sobre o regime jurídico dos servidores públicos civis da União, das autarquias e das fundações públicas federais. Disponível em: <http://www.planalto.gov.br/ccivil_03/LEIS/L8112cons.htm>. Acesso em 24 mar. 2021.

BRASIL. Lei no. 12.527, de 18 de novembro de 2011. Regula o acesso a informações previsto no inciso XXXIII do art. $5^{\circ}$, no inciso II do $\S 3^{\circ}$ do art. 37 e no $\S$ $2^{\circ}$ do art. 216 da Constituição Federal; altera a Lei №. 8.112, de 11 de dezembro de 1990; revoga a Lei oㅜ 11.111, de 5 de maio de 2005, e dispositivos da Lei o․ 8.159, de 8 de janeiro de 1991; e dá outras providências. Diário Oficial da República Federativa do Brasil, Brasília, 18 nov. 2011. Disponível em: <http://www.planalto.gov.r/ccivil_03/_ato2011-2014/2011/lei//12527.htm>. Acesso em: 24 mar. 2021.

CORREIOS. História dos Correios no Brasil. Brasil, 17 dez 2019. Disponível em:<https://www.correiosbrasil.org/historia-dos-correios/\#HistoriaPostal>. Acesso em: 24 mar. 2021.

MANCOD. Manual de Controle Disciplinar. Disponível em: $<$ https://www.correios.com.br/acesso-ainformacao/Servidores/pdf/MANCOD2020v1.0VIG10.03.2020.pdf> Acesso em: 24 mar. 2021. 
SARAIVA André. A implementação do Sistema Eletrônico de Informações - SEI. Casos SEGES: ENAP, Brasília, p.1-11, 01 out. 2018. Estudo de caso publicado na Casoteca de Gestão Pública.

SILVA, Lino Martins da. Contabilidade Governamental: um enfoque administrativo. 4ª ed. São Paulo: Atlas, 2000.

Enviado: Setembro, 2021.

Aprovado: Dezembro, 2021. 